\title{
Cognitive skill learning in amnesia
}

\author{
LARRY R. SQUIRE \\ Veterans Administration Medical Center, San Diego, California \\ and University of California School of Medicine, La Jolla, California \\ and \\ MARY FRAMBACH \\ California School of Professional Psychology, San Diego, California
}

\begin{abstract}
Amnesic patients and control subjects were trained on a computer-based cognitive skill task. Initially, the amnesic patients improved at a normal rate. A separate group of normal subjects did not improve on the task when they received random feedback from the computer on each trial. One month later, when additional training on the task was given, the control subjects performed better than the amnesic patients. There was little if any transfer by either group to a second skill task that had a different surface appearance but which required the identical cognitive strategy. Questionnaire data showed that the control subjects, but not the amnesic patients, acquired declarative knowledge about the strategy needed to perform the task. The findings show that cognitive skill learning can initially proceed at a normal rate in amnesia, presumably because declarative knowledge makes no material contribution to performance early in training. However, declarative knowledge may make an important contribution later in training and may therefore give normal subjects an advantage over amnesic patients.
\end{abstract}

One important focus of recent work on the organization and neurological foundations of memory has been the idea that memory is composed of multiple processes or systems. Although evidence for this idea has come from several sources, an important and compelling kind of evidence comes from studies of human amnesia (Moscovitch, 1982; Schacter, 1987; Squire, 1982; Weiskrantz, 1987). Despite being severely impaired on tasks that require recall or recognition of recently encountered facts and events, amnesic patients can nevertheless acquire certain kinds of skills at a normal rate, including motor skills such as pursuit rotor learning (Brooks \& Baddeley, 1976) and perceptual skills such as reading mirror-reversed words (Cohen \& Squire, 1980). Amnesic patients also exhibit intact word priming (Schacter \& Graf, 1986; Shimamura, 1986), normal shifts in preference following exposure to novel stimuli (Johnson, Kim, \& Risse, 1985), intact adaptation-level effects (Benzing \& Squire, 1989), and intact simple classical conditioning (Daum, Channon, \& Canavar, 1989). These findings suggest that amnesia has revealed a natural division between kinds of learning and memory: some kinds are dependent on the structures and connections damaged in amnesia, and other kinds are in-

This research was supported by the Medical Research Service of the Veterans Administration, NIMH Grant MH24600, the Office of Naval Research, the McKnight Foundation, and a Bioscience Grant for International Joint Research Project from NEDO, Japan. We thank Carolyn Cave, Kathleen Fuchs, and Teresa Doksum for their assistance. After we completed this study, we became aware of similar work by Elizabeth Phelps and we thank her for making her doctoral dissertation available to us. Correspondence may be addressed to Larry R. Squire, Department of Psychiatry, University of California School of Medicine, La Jolla, CA 92093. dependent of these structures and connections (Squire, 1987; Squire, Shimamura, \& Amaral, 1989).

One approach in distinguishing what is spared from what is intact in amnesia emphasizes the difference between explicit and implicit remembering (Schacter, 1987) or declarative and nondeclarative knowledge (Cohen, 1984; Squire, 1982; Squire \& Zola-Morgan, 1988). Amnesic patients fail tasks that depend on the acquisition and storage of declarative knowledge. That is, they fail tasks in which memory is ordinarily expressed as a conscious recollection of a previously learned event or fact. By contrast, amnesic patients succeed when memory is expressed as a change in performance and when there is no requirement for conscious remembering.

The capacity of amnesic patients for cognitive skill learning is not well understood. Although motor and perceptual skill learning can be intact in amnesia, there are few, if any, well-documented examples of normal cognitive skill learning. The Tower of Hanoi problem (Anzai \& Simon, 1979) was initially reported to be acquired normally by Patient H.M. and 11 other amnesic patients (Cohen, 1984; Cohen, Eichenbaum, Deacedo, \& Corkin, 1985). However, this finding was not replicated in a different patient group (Butters, Wolfe, Martone, Granholm, \& Cermak, 1985). Subsequently, it was suggested that the original observation of normal acquisition by amnesic patients depended on the frequent use of prompts and cues during learning (Gabrieli, Keane, \& Corkin, 1987). Computer vocabulary terms and simple programming skills can be acquired by amnesic patients but at an abnormally slow rate (Glisky, Schacter, \& Tulving, 1986a, 1986b). The learning of an arithmetical rule occurred at a normal rate in 1 amnesic patient but not in 
2 others (Charness, Milberg, \& Alexander, 1988; Milberg, Alexander, Charness, McClinchey-Berroth, \& Barrett, 1988). One reason that cognitive skill learning may not proceed normally in amnesic patients is that many such tasks depend on both declarative and nondeclarative memory abilities (Shimamura \& Squire, 1988; Willingham, Nissen, \& Bullemer, 1989). Amnesic patients should exhibit entirely intact cognitive skill learning only when declarative memory makes no material contribution to the task under study.

By one view, cognitive skill learning in normal subjects typically begins with declarative propositions (Anderson, 1987). If this is so, amnesic patients should never exhibit fully intact acquisition of cognitive skills. Yet normal subjects can reportedly acquire rule-based information in the absence of awareness about what was learned, which suggests that such learning is nondeclarative ( $\mathrm{Re}$ ber, 1976; Willingham et al., 1989). Also, in tasks of cognitive skill learning, explicit and implicit aspects of learning can be dissociated, and considerable implicit knowledge can develop for a task in the absence of detectable explicit knowledge (Berry \& Broadbent, 1984, 1988).

In one interesting series of studies, amnesic patients learned a nonverbal serial reaction-time task at a normal rate (Nissen \& Bullemer, 1987; Nissen, Willingham, \& Hartman, 1989). Additional studies with young normal subjects showed that learning could occur in the absence of declarative knowledge about what was learned, that further training increased their declarative knowledge, and that the skill was not strictly perceptual or motor but consisted of a highly specific set of production rules (i.e., rules that map stimuli onto responses). The skill showed minimal transfer to a different setting that required identical motor responses (Willingham et al., 1989).

The purpose of the present study was threefold. First, we asked whether amnesic patients can acquire a purely cognitive skill at a normal rate. We reasoned that if learning of the skill depends entirely on nondeclarative memory, amnesic patients should be able to acquire it normally. Second, building on the finding that extended training on a skill task can make available declarative knowledge about the required responses (Willingham et al., 1989), we asked whether normal subjects would eventually perform better than amnesic patients. Third, we explored the extent of transfer between the training task and a task that was superficially different but which required the identical strategy. Two computer-based tasks were used (Berry \& Broadbent, 1984), in which subjects were asked to achieve and then maintain desired values of an output variable by varying an input variable. Although the tasks were superficially quite different, the equation relating the two variables was identical.

\section{EXPERIMENT 1}

\section{Method}

\begin{abstract}
Subjects
Amnesic patients. Fourteen amnesic patients were tested: 7 with alcoholic Korsakoff's syndrome, 3 with amnesia due to an anoxic or ischemic episode, 1 with amnesia due to a bilateral thalamic infarction, 2 with amnesia of uncertain origin, and Patient N.A. (Table 1). The patients with Korsakoff's syndrome (5 men and 2 women) have been studied as a group for 3 years (Janowsky, Shimamura, Kritchevsky, \& Squire, 1989; Squire, Haist, \&
\end{abstract}

Table 1

Description of Amnesic Patients

\begin{tabular}{|c|c|c|c|c|c|c|c|c|}
\hline \multirow[b]{2}{*}{ Patient } & \multirow[b]{2}{*}{$\begin{array}{c}\text { Age } \\
\text { (years) }\end{array}$} & \multirow[b]{2}{*}{ Education } & \multirow[b]{2}{*}{ WAIS-R } & \multicolumn{5}{|c|}{ WMS-R } \\
\hline & & & & $\begin{array}{c}\text { Attention/ } \\
\text { Concentration }\end{array}$ & Verbal & Visual & General & Delay \\
\hline \multicolumn{9}{|c|}{ Korsakoff Patients } \\
\hline N.C. & 45 & 12 & 90 & 62 & 80 & 60 & 69 & $<50$ \\
\hline V.F. & 68 & 10 & 103 & 101 & 78 & 72 & 72 & 66 \\
\hline B.L. & 50 & 12 & 88 & 80 & 77 & 83 & 75 & 57 \\
\hline D.M. & 54 & 12 & 101 & 92 & 55 & 64 & $<50$ & 51 \\
\hline P.N. & 61 & 11 & 94 & 81 & 77 & 73 & 67 & 53 \\
\hline J.W. & 52 & 14 & 98 & 104 & 65 & 70 & 57 & 57 \\
\hline R.C. & 72 & 9 & 106 & 115 & 76 & 97 & 80 & 72 \\
\hline \multicolumn{9}{|c|}{ Other Amnesics } \\
\hline N.A. & 49 & 13 & 120 & 102 & 67 & 89 & 68 & 71 \\
\hline A.B. & 51 & 21 & 119 & 87 & 62 & 72 & 54 & $<50$ \\
\hline G.D. & 48 & 13 & 92 & 109 & 86 & 88 & 85 & 60 \\
\hline M.G. & 56 & 13 & 111 & 111 & 82 & 68 & 69 & 50 \\
\hline W.I. & 75 & 12 & 104 & 92 & 72 & 82 & 71 & 58 \\
\hline J.L. & 69 & 14 & 104 & 122 & 73 & 83 & 74 & 58 \\
\hline L.M. & 58 & 15 & 111 & 132 & 87 & 96 & 90 & 65 \\
\hline$M$ & 57.7 & 12.9 & 102.9 & 99.3 & 74.1 & 78.4 & 70.1 & 58.4 \\
\hline
\end{tabular}

Note-The WMS-R does not provide numerical scores for subjects who score below 50 . Therefore, values below $\mathbf{5 0}$ were scored as $\mathbf{5 0}$ to compute group means. WAIS-R $=$ Wechsler Adult Intelligence Scale-Revised Full Scale IQ, WMS-R = Wechsler Memory ScaleRevised. 
Shimamura, 1989). Their memory impairment has been documented previously (patients K1-K7 in Squire, Haist, \& Shimamura, 1989; also, the first 6 patients listed in Table 1 correspond to patients K1-K6 in Squire \& Shimamura, 1986). Of the 7 other patients, A.B. became amnesic in 1976 following an anoxic episode during a cardiac arrest, G.D. became amnesic in 1983 following a period of hypotension that occurred during major surgery, L.M. became amnesic in 1984 as the result of a respiratory arrest that occurred during an epileptic seizure, and M.G. became amnesic in 1986 following a bilateral thalamic infarction that was confirmed by magnetic resonance (MR) scans. W.I. and J.L. both became amnesic gradually during a period of about 2 years (for W.I., 1983-1985; for J.L., 1985-1987), but without any known precipitating event. Their cognitive status has remained stable since their amnesia developed. MR scans for L.M., W.I., and J.L. have identified bilateral abnormalities in the hippocampal formation (for L.M. and J.L., see Press, Amaral, \& Squire, 1989). Finally, N.A. became amnesic in 1960 when he sustained a stab wound to the left diencephalic region with a miniature fencing foil (Squire, Amaral, Zola-Morgan, Kritchevsky, \& Press, 1989; Teuber, Milner, \& Vaughan, 1968). In the present study, the results obtained for the patients with Korsakoff's syndrome were identical to the results for the other amnesic patients; thus, all 14 patients are presented here as a single group.

The 14 patients averaged 57.7 years of age at the beginning of the study. They had an average of 12.9 years of education and a mean of 102.9 on the Wechsler Adult Intelligence ScaleRevised (WAIS-R). Their immediate and delayed recall (12 min) of a short prose passage averaged 5.6 and 0 segments, respectively (21 segments total). Their copy and delayed (12-min) recall of the Rey-Osterrieth Complex Figure (Lezak, 1983; Osterrieth, 1944) averaged 27.4 and 4.4 , respectively (36 segments total). Their paired-associate memory for 10 unrelated word pairs on each of three successive trials averaged $0.6,0.4$, and 1.8 . Their free recall of 15 words (Rey auditory verbal learning test; Lezak, 1983; Rey, 1964 ) averaged $4.3,4.9,5.4,5.4$, and 5.5 words on five successive study/test trials. Note that the scores are above zero because on this test of immediate recall, several items can be retrieved from immediate memory, which is intact in amnesia. Yes/no recognition of 15 previously presented words and 15 new words across five successive study/test trials averaged $21.7,25.0,24.9,26.4$, and 27.3 correct responses.

Neurological screening and independent neurological examination indicated that memory impairment was the only remarkable deficit of higher cortical function. The amnesic patients averaged 131.9 out of a possible 144 points on the Dementia Rating Scale (Mattis, 1976), losing most of their points (average $=6.7$ points) on the memory subportion of the test. Additional neuropsychological data for 10 of these 14 patients ( 6 of the 7 Korsakoff patients and Patients N.A., A.B., G.D., and L.M.), as well as scores for control subjects on all the aforementioned tests, can be found in Squire and Shimamura (1986).

Control subjects. Twenty healthy control subjects ( 10 men and 10 women) served as a control group. All were volunteers or employees at the San Diego Veterans Administration Medical Center. They averaged 56.9 years of age at the beginning of the study, had 14.4 years of education, and had WAIS-R subtest scores of 20.3 for Information (vs. 19.4 for the patients) and 52.2 for Vocabulary (vs. 51.8 for the patients). For these subjects, immediate and delayed $(12-\mathrm{min})$ recall of a short prose passage averaged 7.6 and $6.4 \mathrm{seg}$ ments, respectively.

Control subjects (random feedback). Eighteen healthy subjects ( 9 women and 9 men) served in an additional control group to determine whether improved performance by the two other subject groups could be attributed to the learning of specific rule-based behavior, or whether improved performance might reflect some general response bias that is unrelated to the feedback that subjects receive. This group of subjects were either employees at the San Diego Vet- erans Administration Medical Center or were recruited from the community (mean age $=60.3$ years, education $=13.7$ years, WAIS-R subtest scores $=\mathbf{2 0 . 8}$ for Information and 51.0 for Vocabulary). These subjects' immediate and delayed recall of a short prose passage averaged 7.0 and 5.8 segments, respectively.

\section{Tasks and Procedure}

Two computer-based tasks were used, as described by Berry and Broadbent (1984). Both tasks required the subjects to interact with a computer (an Apple Ile) to maintain a specific target value across trials. Only the first task, sugar production, was considered in Experiment 1 . The subjects were told to imagine that they were the president of a sugar-production factory and that they could control the level of production by determining on each trial the number of workers that should be hired. The number of workers hired could vary in 12 discrete steps from 100 to 1,200 , and sugar production could also vary in 12 discrete steps, from 1,000 to 12,000 tons.

The subjects were instructed that their task was to hire the number of workers needed to produce 9,000 tons of sugar, and that they should try to achieve that level of production on every trial. At the outset, the computer always displayed the same starting level: 600 workers had been hired, and these workers had produced 6,000 tons of sugar. The subjects began by typing in a digit from 1 to 12 to represent the number of workers hired (100 to 1,200$)$. The computer responded by displaying a vertical bar graph to represent the sugar-production level achieved on that trial $(1,000$ to 12,000 tons). Bar graphs resulting from successive trials remained on the screen until 30 trials had been completed. In addition, the number of workers hired on the previous trial was always in view. Thus, the vertical axis represented sugar production (1,000-12,000 tons) and the horizontal axis represented trials (1-30). A horizontal dotted line crossing the screen served to remind the subjects of the target production level $(9,000$ tons). An illustrative series of possible inputs (number of workers hired) and outputs (level of sugar production) is shown in Figure 1. The objective of the task (produce 9,000 tons of sugar) was printed on a card and was in view at all times. The computer keyboard was covered except for the keys necessary to perform the task.

The production level was related to the number of workers hired by the equation $P=(2 \times W)-P 1$, where $W=$ the number between 1 and 12 typed by the subject to represent the number of workers hired, $P 1=$ the previous sugar production (i.e., the previous sugar production in tons divided by 1,000 ), and $P=$ the current sugar production (from 1 to 12 , which represents thousands of tons). The computer randomly added 1,0 , or -1 to $P$ on each trial, so that there would be only an approximate, rather than an exact, relationship between the work force and the production level. Finally, the value of $P$ was automatically adjusted, if necessary, so that it was never less than 1 or greater than 12 .

When 30 trials were completed, the screen was cleared, except for a display of the subject's most recent work-force selection and the most recent production level, and the subjects continued to work on the task for two additional blocks of 30 trials (total $=90$ trials). Following Berry and Broadbent's (1984) procedure, the score for each block of 30 trials was the number of trials on which 8,000 , 9,000 , or 10,000 tons of sugar were produced (the subjects were unaware of this scoring criterion). The results were the same when a stricter scoring criterion was employed (i.e., the number of trials on which exactly 9,000 tons of sugar were produced).

Note that the production level achieved on each trial depended on both the previous production level and the number of new workers hired. Accordingly, the subjects learned to respond differently depending on the level of production achieved on the previous trial. In addition, the random element discouraged the subjects from acquiring fixed responses to the different possible starting conditions.

Once the subjects had completed 90 trials on the sugar-production task, they were given 16 questions, multiple choice with five alternatives, which assessed declarative (explicit) knowledge about the 


\section{SUGAR PRODUCTION CHART}

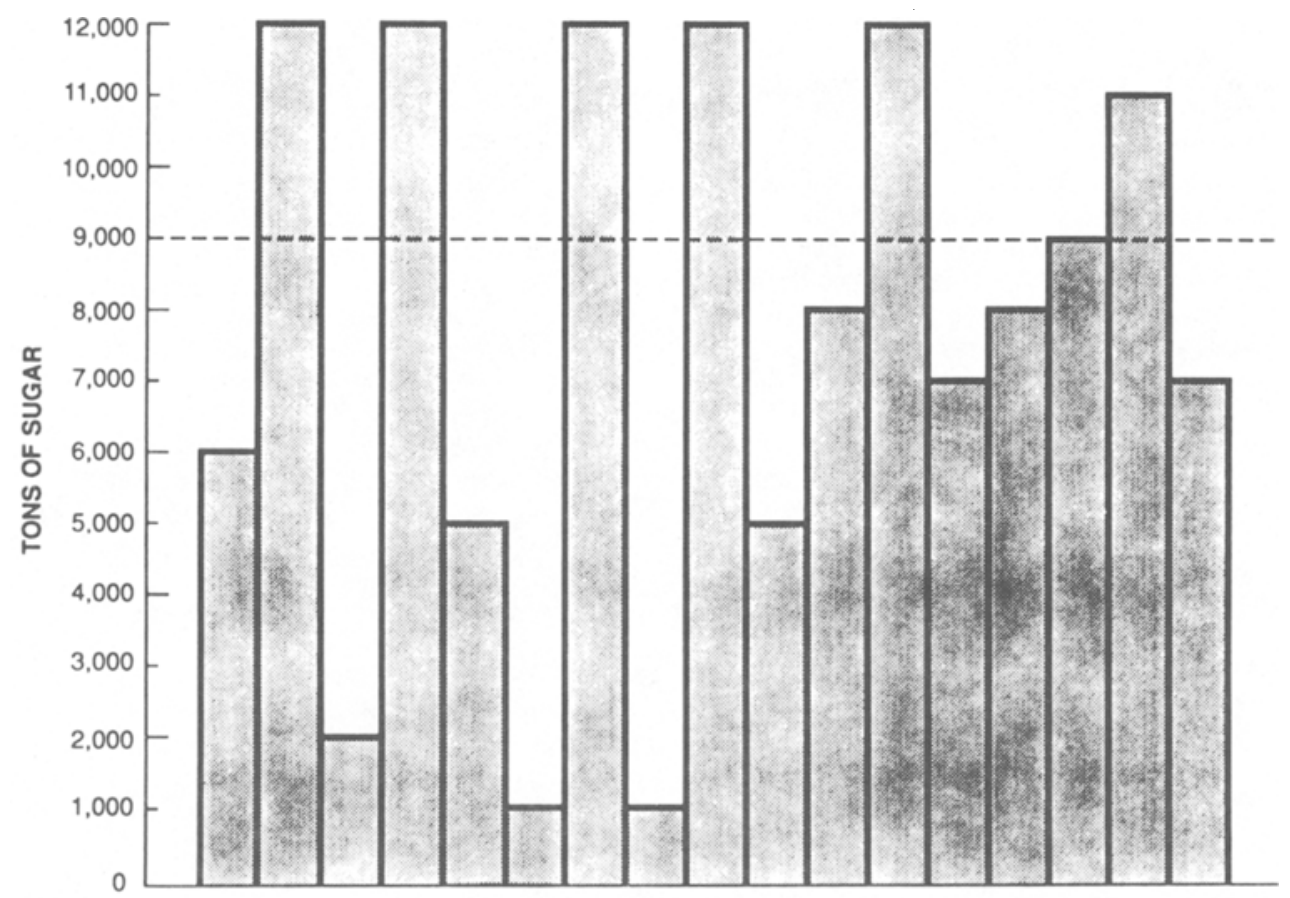

6009006001200900100900700700900700100010008009001000900

WORKERS HIRED

Figure 1. Appearance of the computer screen after a hypothetical series of 12 trials in the sugar-production task. The results for the first trial were always provided by the computer: 600 workers had been hired, and they had produced 6,000 tons of sugar. On subsequent trials, the subject decides how many workers to hire with the objective of achieving a production level of 9,000 tons of sugar. Production levels of $9,000 \pm 1,000$ tons are scored as correct. Thus, 3 of the 12 trials shown here would have been scored as correct. In the task itself, subjects can see the number of workers hired only on the most recent trial.

task. The questions were of three types (Table 2). Seven questions assessed memory for simple facts about the task. Four questions assessed how well the subjects understood the general strategy for performing the task. The five remaining questions were intended to duplicate the ones used by Berry and Broadbent (1984) and assessed how well the subjects understood the specific strategy [i.e., the relationship between their input (number of workers hired) and the computer output (tons of sugar production)]. Two of these five questions provided starting values (the most recent level of production and a new level of work force) and asked how much sugar would be produced; the other three questions provided graphs, similar to the sugar-production chart on the computer, and asked the subjects to predict the level of sugar production that would result when a specific number of workers were hired.

After completing the questionnaire, the subjects also worked on a second computer-based task (personal interaction) and were asked three questions to determine how similar they found the two tasks. (These results will be considered as part of Experiment 2). Then, after an average interval of 27 days (range $=21-49$ ), the subjects were tested again in the identical way (Session 2).

Control group (random feedback). A separate group of normal subjects also completed 90 triais on the sugar-production task, but the feedback given after each trial (i.e., tons of sugar produced) was random and bore no relation to the number of workers the subject chose to hire on each trial. A score for each block of 30 trials was subsequently obtained by entering each subject's 90 responses into the standard sugar-production task. The computer calculated the level of sugar production for each trial by applying the same equation that was used during ordinary training. The score was the number of trials on which $8,000,9,000$, or 10,000 tons of sugar were produced.

\section{Summary of Experimental Design}

The subjects first worked on the sugar-production task for 90 trials (Session 1) and then completed the 16-item questionnaire. After completing the questionnaire, the subjects worked on a second computer-based task, personal interaction, which required precisely the same strategy (Berry \& Broadbent, 1984; see Experiment 2). Then, after an average of 27 days, all subjects were tested again in the identical way (Session 2). A separate group of subjects also worked on the sugar-production task for 90 trials, but the feedback given by the computer was random and was not related to the subjects' responses.

\section{Results}

Figure 2 shows performance on the sugar-production task. The data were analyzed separately for the two sessions. In Session 1, both groups learned similarly. There was a significant effect of trial blocks $[F(2,64)=4.6$, $p<.05]$, but no effect of group $[F(1,32)=0.4$, $p>.10]$ and no group $\times$ trial interaction $[F(2,64)=$ $1.2, p>.10]$. Additional analyses of linear trend as- 
Table 2

Sample Questions

\section{Facts}

This task was played on what brand of computer?
a. IBM
b. Panasonic
*c. Apple
d. Commodore
e. Leading Edge

General Strategy

A possible strategy employed to reach the target level would include:

*a. increasing or decreasing the number of workers hired in small increments

b. increasing or decreasing the number of workers hired in large increments

c. tending to hire extreme amounts of workers (either 100 or 1,200 workers)

d. subtracting the previous month's output from the current number of workers hired in order to predict the next month's output

e. hiring 100 more workers each month regardless of the production level

Specific Strategy

The initial production level is 6,000 and the initial work force is 600 . If you increase the work force to 900 workers, the resulting production output would be:

a. 6,000

b. 9,000

c. between 6,000 and 9,000

d. less than 6,000

*e. more than 9,000

*Correct answer. sessed the extent of learning within each group. The amnesic patients improved across trial blocks $[F(1,26)=$ $5.1, p<.05$ ]; for the control subjects, the linear trend test fell just short of significance $[F(1,38)=3.3$, $p<.08$.

During the second session, which occurred an average of 27 days after the first, learning also occurred. However, now the control subjects performed better than the amnesic patients. There was a significant effect of trial blocks $[F(2,64)=6.3, p<.01]$ and a significant effect of group $[F(1,32)=5.2, p<.05]$, but no interaction $[F(2,64)=$ $0.4, p>.10]$. Separate analyses of linear trend indicated significant improvement across trials for the control subjects $[F(1,32)=7.8, p<.01]$; for the amnesic patients, the linear trend test fell short of significance $[F(1,26)=$ $3.4, p=.08$ ]. Comparisons between the two sessions showed that the control subjects performed somewhat better in the second session than they did in the first session $[F(1,19)=3.6, p=.07]$. The amnesic patients performed almost identically in the two sessions $[F(1,13)=$ $0.01, p>.10]$.

Table 3 shows performance in each session on the 16-item questionnaire. The scores on the two sessions, averaged across the 16 items, were very similar $[F(1,32)=1.14, p>.10]$, and the control subjects performed better than the amnesic patients $[F(1,32)=34.5$, $p<.001]$. As would be expected, the control subjects answered simple factual questions about the test much

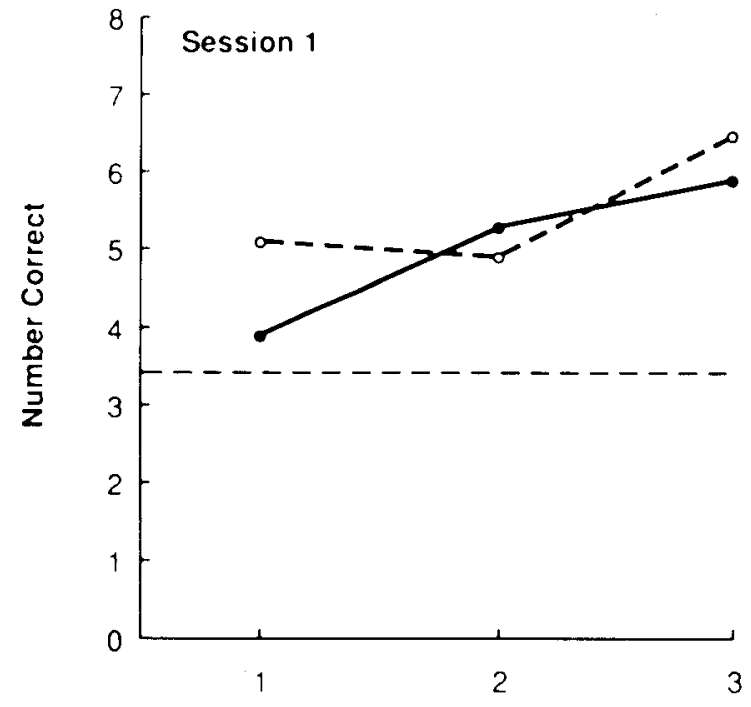

Blocks of 30 Trials

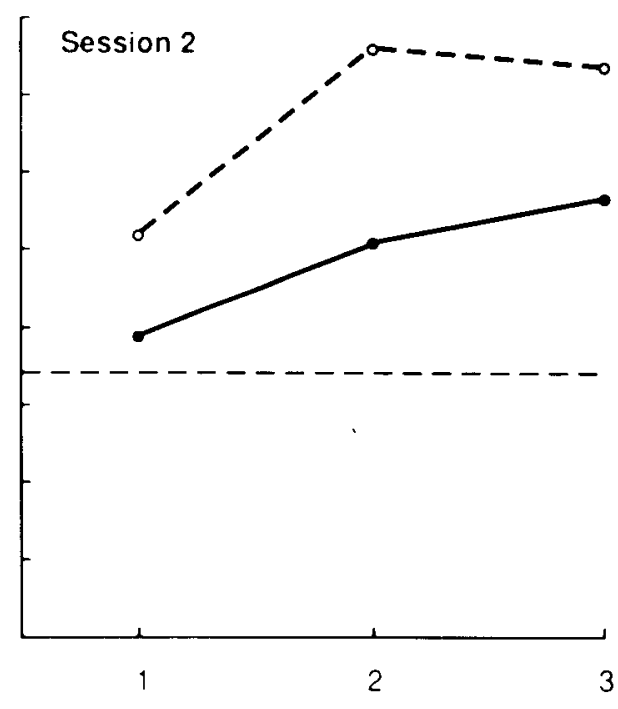

Blocks of 30 Trials

Figure 2. Performance on the sugar-production task by amnesic patients ( $n=14$, solid lines) and control subjects ( $n=$ 20, dashed lines). The subjects worked on the task for 90 trials on Session 1 and then, 27 days later on average, they worked on the same task for an additional 90 trials. The horizontal dashed lines show chance performance as calculated by a computer simulation in which the 12 responses available to the subject were chosen on each trial with equal probability (Berry \& Broadbent, 1984). 
Table 3

Questionnaire Performance by Question Type

\begin{tabular}{|c|c|c|c|c|c|c|}
\hline \multirow[b]{2}{*}{ Subjects } & \multicolumn{3}{|c|}{ Session 1} & \multicolumn{3}{|c|}{ Session 2} \\
\hline & Facts & $\begin{array}{l}\text { General } \\
\text { Strategy }\end{array}$ & $\begin{array}{l}\text { Specific } \\
\text { Strategy }\end{array}$ & Facts & $\begin{array}{l}\text { General } \\
\text { Strategy }\end{array}$ & $\begin{array}{l}\text { Specific } \\
\text { Strategy }\end{array}$ \\
\hline & $79.2^{*}$ & & & $89.4^{*}$ & $61.2 *$ & $32.0^{*}$ \\
\hline Amnesics & 50.0 & $28.6 \dagger$ & 30.0 & 51.1 & 35.7 & $22.9 \dagger$ \\
\hline
\end{tabular}

Note-Data represent percent correct. *Significantly greater than the corresponding amnesic score. †Not significantly different from the chance value of $20 \%$.

more accurately than the amnesic patients (Session 1, $79.2 \%$ vs. $50.0 \%$; Session $2,89.4 \%$ vs. $51.1 \%$; $p s<.001)$. In contrast, neither the control subjects nor the amnesic patients were able to answer specific questions about how the task worked; that is, despite the fact that they had been improving gradually at the task, they were quite poor at predicting the computer's response given a particular input (Session 1, controls, 36.0\%, amnesics, 30.0\%; Session 2, controls, $32.0 \%$, amnesics, $22.9 \%$; Table 3). However, the control subjects did acquire some knowledge about how the task should be performed, as reflected by their performance on the questions about general strategy $(55.0 \%$ and $61.2 \%$ correct in Sessions 1 and 2, respectively). By contrast, the amnesic patients acquired little such information $(28.6 \%$ and $35.7 \%$ correct in Sessions 1 and 2 , respectively, chance $=20 \%$; controls vs. amnesics, $p$ s $<.001)$.

The subjects who worked at the test but received random feedback did not improve their performance across trial blocks. The average score for three consecutive blocks of 30 trials was $4.6,4.9$, and 5.1 [test for linear trend, $F(1,34)=0.4, p>.10$ ]. As a result of training, the amnesic patients and trained control subjects improved their scores, whereas the subjects given random feedback did not. Thus, the amnesic patients (as well as the trained control subjects) did acquire information about the specific rule that related the number of workers to sugar production.

\section{EXPERIMENT 2}

In Experiment 2, we assessed how much transfer occurred between the sugar-production task and another computer-based task (personal interaction) that required exactly the same strategy.

\section{Method}

\section{Subjects}

In addition to the subjects from Experiment 1, who worked on the sugar-production task and then on the present personal interaction task described below, 20 additional normal subjects (11 men and 9 women) were tested. These 20 subjects worked on the personal interaction task and then worked on the sugar-production task. The new subjects were volunteers or employees at the San Diego Veterans Administration Medical Center. They averaged 56.5 years of age at the beginning of the study, had 14.1 years of education, and had WAIS-R subtest score averages of 21.3 for Information and 51.9 for Vocabulary. For these subjects, immediate and delayed (12-min) recall of a short prose passage averaged 7.3 and 6.4 segments, respectively.

\section{Tasks}

The sugar-production task has already been described. The personal interaction task (Berry \& Broadbent, 1984) required the subjects to interact with a computer "person" named Clegg, who could exhibit any of 12 styles of behavior ("loving," "very affectionate," "affectionate," "very friendly," "friendly," "very polite," "polite," " indifferent," "cool," "very cool," "rude," and "very rude"). Clegg initiated the interaction by displaying an "indifferent," a "polite," or a "very polite"' response. The subjects were instructed to communicate with Clegg using one of the same 12 behaviors and to attempt to get Clegg to be "very friendly" as often as possible. Clegg's responses on each trial were computed using exactly the same formula used in the sugar-production task. (In this case, the numbers from 1 to 12 were associated with one of the 12 behaviors, and the target value "very friendly" corresponded to 9,000 in the sugar-production task.)

The subjects began by typing in a two-letter code corresponding to the behavior they wished to communicate (e.g., VF for "very friendly," PO for "polite"). All but the necessary computer keys were covered, and the task objective (to make Clegg "very friendly") was printed on a card and in full view. A list of the 12 codes and corresponding behaviors were also available to the subject throughout the task. On each trial, only the interaction on the most recent trial was displayed on the screen. The score for 30 trials was the number of trials in which Clegg's response was "friendly," "very friendly," or "affectionate."

After working on the two skill tasks, all subjects were given a three-item questionnaire to assess how similar or different they found the two computer-based tasks. Specifically, the subjects rated the degree of similarity of the two tasks on a scale from 1 (extremely different) to 5 (extremely similar). The three questions asked about (1) the overall similarity of the two tasks, (2) the similarity of the two tasks excluding the fact that different computer displays were used, and (3) the similarity of the two tasks with respect to the optimal strategy needed to reach the target levels.

\section{Summary of Experimental Design}

Data needed to assess transfer from the sugar-production task to the personal interaction task were collected as part of Experiment 1 (Sessions 1 and 2). Specifically, in both Session 1 and Session 2, the subjects worked on the sugar-production task for 90 trials, then worked on the personal interaction task for 30 trials, and then answered three questions about the similarity between the two tasks. To assess transfer in the opposite direction-from the personal interaction task to the sugar-production task -20 new subjects worked on the personal interaction task for 90 trials and then worked on the sugar-production task for 30 trials. They then answered the three questions about task similarity.

\section{Results}

Table 4 shows the results for the subjects from Experiment 1 who worked for 90 trials on the sugar-production task followed by 30 trials on the personal interaction task, as well as the results for the new subjects in Experiment 2, who worked for 90 trials on the personal interaction task and then for 30 trials on the sugar-production task. Although the two tasks were identical in terms of the formula that related a subject's input to the computer's response, they differed in how readily the subjects acquired the correct strategy. Control subjects in Experiment 2 achieved 30.2 trials correct during 90 trials on the 
Table 4

Transfer Between Tasks

\begin{tabular}{cccccccc}
\hline Experiment & Task & Session & Subjects & Block 1 & Block 2 & Block 3 & 30 Transfer Trials \\
\hline \multirow{2}{*}{1} & \multirow{2}{*}{ Sugar production } & 1 & Controls & 5.2 & 4.8 & 6.6 & 7.5 \\
& & & Amnesics & 3.8 & 5.2 & 6.0 & 5.5 \\
& & 2 & Controls & 5.2 & 7.6 & 7.4 & 9.1 \\
& & & Amnesics & 3.9 & 5.1 & 5.7 & 6.0 \\
2 & \multirow{2}{*}{ Personal interaction } & - & Controls & 9.2 & 10.5 & 10.5 & 6.7 \\
\hline
\end{tabular}

Note-Scores are the mean number of trials correct in successive blocks of 30 trials. Standard errors of the mean ranged from 0.5 to 1.0 .

personal interaction task, whereas control subjects in Experiment 1 achieved only 16.5 trials correct during 90 trials on the sugar-production task $[t(19)=5.3$, $p<.001]$.

The results of the transfer tests gave little evidence for transfer of knowledge from one task domain to the other. Following 90 trials on the sugar-production task, the control subjects from Experiment 1 (Session 1) achieved only 7.5 trials correct out of 30 when they were transferred to the personal interaction task. This score suggests that no transfer occurred, because the naive subjects in Experiment 2 achieved 9.2 trials correct during their first 30 trials on the personal interaction task. Similarly, the subjects in Experiment 2 exhibited an abrupt drop in performance when they were transferred from the personal interaction task to the sugar-production task [from 10.5 trials correct to 6.7 trials correct, $t(19)=2.59, p<.05$ ] However, this score (6.7 correct) cannot be interpreted unambiguously, because it is not measurably different from either the score obtained by the subjects who were just beginning to work on the sugar-production task (5.2 correct during the first 30 trials of Session 1) or the score obtained in Session 1 during the final 30 trials on the sugar-production task (6.6 correct). Finally, the normal subjects from Experiment 1 (Session 2) did perform better on the transfer task (personal interaction) than the amnesic patients $[9.1 \mathrm{vs}$. 6.0 trials correct, $t(32)=2.37$, $p<.05]$. However, this score $(9.1$ correct trials) does not reflect transfer in the normal sense of the term because the naive subjects in Experiment 2 performed just as well on the first 30 trials of the personal interaction test (9.2 correct trials).

When asked the three questions about the similarity of the two tasks, the subjects tended to choose the middle of the 1-5 scale. In general, the results gave no evidence that the subjects recognized much similarity between the two tasks. A three-way analysis of variance (group $\times$ session $\times$ question) revealed no main effects $(F \mathrm{~s}<2.0)$. Control subjects who worked on the sugar-production task during Session 1 of Experiment 1, and were then transferred to the personal interaction task, gave a rating of $3.1 \pm 0.3$, averaged across the three questions. At the end of Session 2, the rating increased slightly $(3.4 \pm 0.2)$. The amnesic patients gave ratings of $3.3 \pm 0.2$ and 3.3 \pm 0.2 after Sessions 1 and 2 , respectively. The subjects who worked in the opposite sequence (Experiment 2) gave a similarity rating of $2.8 \pm 0.2$. Even when the subjects were asked directly about the similarity between the two strategies (Question 3), the ratings were similar across groups and sessions (3.0-3.7). We noted that the highest similarity rating for this question (3.7) and the highest overall rating for all three questions (3.4) was given by the control subjects at the end of Session 2. However, these ratings were not significantly higher than the corresponding ratings given by the control subjects after Session 1 or by the amnesic patients after Sessions 1 or 2 ( $p s>.10)$.

As described above, after extended training (Experiment 1, Session 2), the normal subjects performed better than the amnesic patients on the sugar-production task and also performed better when transferred to the personal interaction task. The control subjects also exhibited more declarative knowledge about the sugar-production task than did the amnesic patients. Thus, the control subjects scored $55.0 \%$ and $61.2 \%$ correct at the end of Sessions 1 and 2, respectively, for the questions about the general strategy needed to perform the task, whereas the amnesic patients scored only $28.6 \%$ and $35.7 \%$, respectively.

We next carried out correlational analyses to explore whether the availability of declarative knowledge might have facilitated the performance of the normal subjects on the skill tasks in Session 2. We calculated for each session all of the pairwise correlations $(n=6)$ involving four measures for the amnesic patients and control subjects separately: performance during 90 trials on the sugarproduction task, performance during 30 transfer trials on the personal interaction task, performance on the four questions about the general strategy needed to perform the task, and performance on the three questions about task similarity. These 24 correlations were mostly low and nonsignificant, although the correlations calculated for the control subjects in Session 2 tended to be a little higher than the others. For this group, the average for all six correlations was $r=.30$. This value was not significant $(p>.10)$, but it is mentioned because the average of the same six correlations for the amnesic patients was -.06 and .03 for Sessions 1 and 2, respectively, and .12 for the normal subjects in Session 1 .

Having noted that the normal subjects acquired more declarative knowledge about the skill tasks than did the amnesic patients, it should also be emphasized that they acquired only a modest amount of declarative knowledge. For example, although the normal subjects did acquire knowledge about the general strategy needed to perform the task, even at the end of Session 2 they could answer 
only $32 \%$ of the five questions that reproduced specific task situations (chance $=20 \%$ ). Moreover, they did not detect much similarity between the two skill tasks (average similarity rating $=3.4$ on a $1-5$ scale).

\section{DISCUSSION}

Fourteen amnesic patients exhibited intact learning of a cognitive skill during the early stages of training. This learning reflected the acquisition of specific information about a rule, as provided in the feedback given to the subjects on each trial. The control subjects given random feedback did not improve their performance. When additional training on the skill was given about 1 month later, the normal subjects performed better than the amnesic patients. These findings extend the demonstration of preserved learning in amnesia to a purely cognitive skillthat is, a skill that is neither strictly perceptual nor motor. Recently, 5 amnesic patients were found to improve at a normal rate on a different computer-based problemsolving task (Phelps, 1989). The present study and the one by Phelps together provide strong evidence that cognitive skill learning can proceed at a normal rate in amnesia.

In general, the findings with normal subjects confirmed the observations of Berry and Broadbent (1984), which were based on the same task. However, two differences were noted. First, whereas the Oxford undergraduates tested in their study quickly developed considerable proficiency in the task (16.2 trials correct on the second block of 30 trials), the older subjects in the present study improved slowly and, even with additional training, showed only a modest level of proficiency (6.5 trials correct on the third block of 30 trials). Age and educational background are likely to be important determinants of performance on cognitive skill tasks. Second, although we confirmed Berry and Broadbent's finding of a dissociation between subjects' ability to perform the task and their ability to answer questions about which responses should be made in particular situations, it would be incorrect to conclude that no declarative knowledge at all was acquired. In questionnaires administered at the end of each training session, the normal subjects (but not the amnesic patients) were able to answer general strategy questions about the task.

Extended training on the skill task may have benefited the control subjects more than the amnesic patients by affording them declarative knowledge that could then be applied to the task. This idea is supported by other work involving a different skill task, which showed that extended training gradually leads to more declarative knowledge and to better skilled performance (Willingham et al., 1989). Also, in that same study, for a given number of training trials, subjects who acquired more declarative knowledge about the skill (in this case, subjects who became aware of the required responses) performed better than subjects who did not acquire such knowledge.

In the present study, the control subjects did acquire more declarative knowledge about the task than amnesic patients did, as reflected in their ability to answer the general strategy questions, and they also performed better on the skill task. Although it seems reasonable to suppose that such declarative knowledge benefited skill performance, we did not obtain strong, direct evidence for this idea. First, the relevant correlational data were inconclusive. Second, virtually the same degree of declarative knowledge was available to the control subjects at the end of both Session 1 and Session 2, yet the control subjects performed better than the amnesic patients only during Session 2. One possibility is that the declarative knowledge exhibited at the end of Session 1 became available too late in the session to materially benefit the skill measure. Unfortunately, no data are available on this point.

What is clear is that early-stage learning of cognitive skill tasks need not depend materially on declarative knowledge. If it did, the amnesic patients should not have been able to keep pace with the normal subjects during 90 trials of training on the sugar-production task. It might be supposed that the amnesic patients learned the task through the accumulation of declarative knowledge, which was held in working (short-term) memory during the $\mathbf{9 0}$ trials of the skill task. This is very unlikely. Neither the amnesic patients nor the normal subjects could answer task-specific questions that were posed immediately upon completion of these 90 trials, even though the questions precisely reproduced the task situation that the subjects had just been working on with increasing success. Also, the amnesic patients could not answer questions about the general strategy of the task immediately after completing 90 trials. If the amnesic patients did not have either specific or general declarative knowledge about the task available immediately upon completing it, it is not clear what kind of declarative knowledge could have been guiding their improvement. Finally, it is worth mentioning that amnesic patients find it difficult to keep anything in mind continuously, as during the $20-40$ min needed to complete 90 trials on this task.

As has been observed in other skill tasks (Willingham et al., 1989), there was minimal transfer of the cognitive skill to another situation that involved the identical cognitive strategy. Thus, skilled behavior can be highly specific. Our data do not permit a conclusion about the important and interesting question as to whether the acquisition of declarative knowledge can facilitate the transfer of skilled behavior. In the present study, even the normal subjects acquired only a limited amount of declarative knowledge, and little if any transfer occurred. When two tasks are as different in their surface appearance as these two were, it is possible that there are distinct limits on the transfer of declarative knowledge, just as there are limits on the transfer of nondeclarative knowledge. Alternatively, if sufficient levels of declarative knowledge were acquired, transfer might occur between two tasks even when they are as different in appearance as the ones used here. This is an important issue for further study.

The present results are in accord with the conclusions of Nissen and her colleagues (Nissen \& Bullemer, 1987; 
Nissen et al., 1989; Willingham et al., 1989) about the development and independence of declarative and procedural knowledge systems. We suggest that early improvement on cognitive skill tasks can occur without a significant contribution from declarative memory, as has been demonstrated previously for other skill tasks that have significant perceptual and motor components (e.g., pursuit rotor learning and mirror reading). As training continues, declarative memory probably makes important contributions. The two kinds of knowledge reflect separate and independent contributions to the performance measure.

\section{REFERENCES}

ANDERSON, J. R. (1987). Skill acquisition: Compilation of weak-method problem solutions. Psychological Review, 94, 192-210.

ANZAI, Y., \& Simon, H. A. (1979). The theory of learning by doing. Psychological Review, 86, 124-140.

Benzing, W. C., \& SQuire, L. R. (1989). Preserved learning and memory in amnesia: Intact adaptation-level effects and learning of stereoscopic depth. Behavioral Neuroscience, 103, 538-547.

Berry, D., BroadBent, D. (1984). On the relationship between task performance and associated verbalizable knowledge. Quarterly Journal of Experimental Psychology, 36A, 209-231.

BERRY, D., \& BroAdBENT, D. (1988). Interactive tasks and the implicitexplicit distinction. British Journal of Psychology, 79, 251-272.

BrooKs, D. N., \& BADDELEY, A. (1976). What can amnesic patients learn? Neuropsychologia, 14, 111-122.

Butters, N., Wolfe, J., Martone, M., Granholm, E., \& Cermak, L. S. (1985). Memory disorders associated with Huntington's disease: Verbal recall, verbal recognition and procedural memory. Neuropsychologia, 23, 729-743.

Charness, N., Milberg, W., \& Alexander, M. P. (1988). Teaching an amnesic a complex cognitive skill. Brain \& Cognition, 8, 253-272.

CoHen, N. J. (1984). Preserved learning capacity in amnesia: Evidence for multiple memory systems. In L. R. Squire \& N. Butters (Eds.), Neuropsychology of memory (pp. 83-103). New York: Guilford.

Cohen, N. J., Eichenbaum, H., Deacedo, B. S., \& Corkin, S. (1985). Different memory systems underlying acquisition of procedural and declarative knowledge. In D. S. Olton, E. Gamzu, \& S. Corkin (Eds.), Memory dysfunctions: An integration of animal and human research from preclinical and clinical perspectives ( $\mathrm{pp}$. 54-71). New York: Annals of the New York Academy of Sciences.

CoHen, N., \&Quire, L. R. (1980). Preserved learning and retention of pattem analyzing skill in amnesia: Dissociation of knowing how and knowing that. Science, 210, 207-209.

Daum, I., Channon, S., \& Canavar, A. (1989). Classical conditioning in patients with severe memory problems. Journal of Neurology, Neurosurgery \& Psychiatry, 52, 47.

Gabrieli, J. D. E., Keane, M. M., \& Corkin, S. (1987). Acquisition of problem-solving skills in global amnesia. Society for Neuroscience Abstracts, 13, 1455.

Glisky, E., Schacter, D., \& Tulving, E. (1986a). Computer learning by memory-impaired patients: Acquisition and retention of complex knowledge. Neuropsychologia, 24, 313-328.

Glisky, E. L., Schacter, D. L., \& Tulving, E. (1986b). Learning and retention of computer-related vocabulary in memory-impaired patients: Method of vanishing cues. Journal of Clinical \& Experimental Neuropsychology, 8, 292-312.

Janowsky, J. S., Shimamura, A. P., Kritchevsky, M., \& SQuire, L. R. (1989). Cognitive impairment following frontal lobe damage and its relevance to human amnesia. Behavioral Neuroscience, 103, 548-560.

Johnson, M. K., KIM, J. K., \& Risse, G. (1985). Do alcoholic Korsakoff's syndrome patients acquire affective reactions? Journal of $E x$ perimental Psychology: Learning, Memory, \& Cognition, 11, 22-36.

LEZAK, M. (1983). Neuropsychological assessment (2nd ed.). Oxford: Oxford University Press.
Mattis, S. (1976). Dementia rating scale. In R. Bellack \& B. Karasu (Eds.), Geriatric psychiatry (pp. 77-121). New York: Grune \& Stratton.

Milberg, W., Alexander, M. P., Charness, N., McClincheyBerroth, R., \& BARRETT, A. (1988). Leaming of a complex arithmetic skill in amnesia: Evidence for a dissociation between compilation and production. Brain \& Cognition, 8, 91-104

Moscovitch, M. (1982). Multiple dissociations of function in amnesia In L. Cermak (Ed.), Human memory and amnesia (pp. 337-370). Hillsdale, NJ: Erlbaum.

Nissen, M. J., Bullemer, P. (1987). Attentional requirements of learning: Evidence from performance measures. Cognitive Psychology, 19, 1-32.

Nissen, M. J., Willingham, D. B., \& Hartman, M. (1989). Explicit and implicit remembering: When is learning preserved in amnesia? Neuropsychologia, 27, 341-352.

OsterRieth, P. A. (1944). Le test de copie d'une figure complexe [The test of copying a complex figure]. Archives de Psychologie, 30 , 206-356.

Phelps, E. A. (1989). Cognitive skill learning in amnesics. Unpublished doctoral dissertation, Princeton University, Princeton, NJ.

Press, G. A., Amaral, D. G., \& Squire, L. R. (1989). Hippocampal abnormalities in amnesic patients revealed by high-resolution magnetic resonance imaging. Nature, 341, 54-57.

REBER, A. S. (1976). Implicit learning of synthetic languages: The role of instructional set. Journal of Experimental Psychology: Human Learning \& Memory, 2, 88-94.

REY, A. (1964). L'examen clinique en psychologie [The clinical exam in psychology]. Paris: Presses Universitaires de France.

SCHACTER, D. L. (1987). Implicit memory: History and current status. Journal of Experimental Psychology: Learning, Memory, \& Cognition, 13, 501-518.

Schacter, D. L., \& Graf, P. (1986). Preserved learning in amnesic patients: Perspectives from research on direct priming. Journal of Clinical Experimental Neuropsychology, 6, 727-743.

Shimamura, A. P. (1986). Priming effects in amnesia: Evidence for a dissociable memory function. Quarterly Journal of Experimental Psychology, 38A, 619-644.

Shimamura, A. P., \& Squire, L. R. (1988). Long-term memory in amnesia: Cued recall, recognition, and confidence ratings. Journal of Experimental Psychology: Learning, Memory, \& Cognition, 14, 763-770.

SQuire, L. R. (1982). The neuropsychology of human memory. Annual Review of Neuroscience, 5, 241-273.

SQuire, L. R. (1987). Memory and brain. New York: Oxford University Press.

SQuire, L. R., Amaral, D. G., Zola-Morgan, S., Kritchevsky, M., \& Press, G. (1989). Description of brain injury in the amnesic patient N.A. based on magnetic resonance imaging. Experimental Neurology, 105, 23-35.

Squire, L. R., Haist, F., \& Shimamura, A. P. (1989). The neurology of memory: Quantitative assessment of retrograde amnesia in two groups of amnesic patients. Journal of Neuroscience, 9, 828-839.

SQuire, L. R., \& Shimamura, A. P. (1986). Characterizing amnesic patients for neurobehavioral study. Behavioral Neuroscience, 100 , 866-877.

Squire, L. R., Shimamura, A. P., \& Amaral, D. G. (1989). Memory and the hippocampus. In J. Byrne \& W. Berry (Eds.), Neural models of plasticity (pp. 208-239). New York: Academic Press.

SQuire, L. R., \& Zola-Morgan, S. (1988). Memory: Brain systems and behavior. Trends in Neuroscience, 11, 170-175.

Teuber, H. L., Milner, B., \& Vaughan, H. G. (1968). Persistent anterograde amnesia after stab wound of the basal brain. Neuropsychologia, 6, 267-282.

WeISKRANTZ, L. (1987). Neuroanatomy of memory and amnesia: A case for multiple memory systems. Human Neurobiology, 6, 93-105.

Willingham, D. B., Nissen, M. J., \& Bullemer, P. (1989). On the development of procedural knowledge. Journal of Experimental Psychology: Learning, Memory, \& Cognition, 15, 1047-1060.

(Manuscript received August 1, 1989; revision accepted for publication January 9, 1990.) 